\title{
A Systematic Literature Review on the Cost- Effectiveness of Apixaban for Stroke Prevention in Non-valvular Atrial Fibrillation
}

\author{
Carme Pinyol (D) Jose $\mathrm{M}^{\mathrm{a}}$ Cepeda $\cdot$ Inmaculada Roldan · Vanesa Roldan \\ Silvia Jimenez $\cdot$ Paloma Gonzalez · Javier Soto
}

Received: April 11, 2016/Published online: July 25, 2016

(C) The Author(s) 2016. This article is published with open access at Springerlink.com

\begin{abstract}
Introduction: Economic evaluations are becoming increasingly important due to limitations in economic resources, the expense

Enhanced content To view enhanced content for this article go to http://www.medengine.com/Redeem/ 56E4F0607849495F.

Electronic supplementary material The online version of this article (doi:10.1007/s40119-016-0066-2) contains supplementary material, which is available to authorized users.
\end{abstract}

C. Pinyol ( $\square)$

INNOVA Strategic Consulting, Barcelona, Spain

e-mail: cpinyol@innovaheor.com

J. M. Cepeda

Internal Medicine Department, Hospital Comarcal

Vega Baja, Orihuela, Alicante, Spain

I. Roldan

Cardiology Department, Hospital La Paz, Madrid, Spain

V. Roldan

Hematology Department, Hospital Morales

Meseguer, Murcia, Spain

S. Jimenez · P. Gonzalez

Health Economics and Outcomes Research,

Bristol-Myers Squibb, Madrid, Spain

J. Soto

Health Economics and Outcomes Research, Pfizer

S.L.U., Madrid, Spain of many new treatments, the need to allocate health spending as effectively as possible, and the need to inform decision makers. Based on the data from the apixaban studies (ARISTOTLE and AVERROES), several economic evaluations have been performed in various countries to demonstrate the efficacy of apixaban versus warfarin and aspirin or other new oral anticoagulants (NOACs) for preventing stroke in patients with non-valvular atrial fibrillation (NVAF).The aim of this study was to perform a systematic literature review of published economic evaluations with apixaban in the indication of stroke prevention in patients with NVAF.

Methods: A search in PubMed, Cochrane Library, Google Scholar, and Index Medicus Español was conducted in June 2015. Inclusion and exclusion criteria were established. The main characteristics were recorded for all relevant articles after being reviewed. In addition, a weighted version of the Drummond's checklist was used to further assess the quality of the selected studies.

Results: After review, 26 cost-effectiveness analyses through Markov models were included; the identified economic evaluations 
represent different willingness-to-pay (WTP) thresholds, discount rates, medical costs, and healthcare systems. Apixaban was compared with warfarin/acenocoumarol in 7 of them (27\%), with warfarin/NOACs in 14 (54\%), with aspirin in $2(8 \%)$, and with warfarin/aspirin in 3 (11\%). Models were conducted from Europe (69\%), USA (23\%), Australia (4\%), and Latin America (4\%). All models reported cost/ quality-adjusted life years (QALYs) gained, $92 \%$ reported using a payer perspective, and $8 \%$ using a societal perspective; the median quality score of the selected studies was 89 (out of 119), with a range of 55-103. In models performed in Europe, incremental cost-effectiveness ratios (ICERs) of apixaban versus warfarin ranged from $€ 5607 / \mathrm{QALY}$ to $€ 57,245 / \mathrm{QALY}$, while ICERs versus aspirin ranged from being dominant to $€ 7334 / \mathrm{QALY}$. In models carried out in the USA, ICERs of apixaban versus warfarin ranged from being dominant to $\$ 93,063 /$ QALY.

Conclusion: Different cost-effectiveness analyses suggest that apixaban is a cost-effective therapeutic option according to the WTP thresholds used in countries where cost-effectiveness analyses, were performed.

Funding: BMS and Pfizer.

Keywords: Apixaban; Economic evaluation; Non-valvular atrial fibrillation; Systematic literature review

\section{INTRODUCTION}

Apixaban is a new oral anticoagulant (NOAC). It is a direct factor $\mathrm{Xa}$ inhibitor with rapid absorption and a 12-h half-life. A total of 25\% is eliminated through renal excretion. Apixaban demonstrated its superior efficacy and safety versus warfarin (gold standard) in preventing stroke in patients with non-valvular atrial fibrillation (NVAF) in the ARISTOTLE study [1] and versus aspirin in the AVERROES study [2] (ClinicalTrials.gov identifiers: NCT00412984 and NCT00496769, respectively). Apixaban belongs to the new generation of anticoagulants with fixed-dose oral administration not requiring laboratory controls and having a little interaction with other drugs and foods [3].

Traditionally, healthcare companies were required to provide evidence to demonstrate product safety, efficacy, and quality for registration and reimbursement purposes. Increasingly, demonstrating value-for-money, which requires companies to conduct economic evaluations to support the reimbursement process, has been added, increasing the importance of health economic evaluations. Some clinical guidelines [4] take cost-effectiveness data into consideration when positioning therapies for stroke prevention in NVAF. Therefore, an important step in determining the place of NOACs in clinical practice is to evaluate their cost-effectiveness in terms of their effect on healthcare decision-making and hence on health outcomes.

In addition, economic evaluations are becoming increasingly important due to limitations in economic resources, the expense of many new treatments, the need to allocate health spending as effectively as possible, and the need to inform decision makers.

Based on the data from the apixaban studies (ARISTOTLE [1] and AVERROES [2]), several economic evaluations have been performed in various countries to demonstrate the efficiency of apixaban versus warfarin and aspirin or other NOACs for preventing stroke in patients with NVAF. 
The aim of this study was to perform a systematic literature review of published economic evaluations with apixaban indicated for stroke prevention in patients with NVAF.

\section{METHODS}

\section{Search Strategy}

Once the search topic was established: "Economic evaluation of apixaban in the indication of stroke prevention in patients with NVAF in Spain and in other countries", we conducted a systematic literature search in PubMed, Cochrane Library, Google Scholar, and Index Medicus Español (IME) in June 2015 based on the following strategy: “(apixaban) AND (cost-effectiveness OR efficiency OR economic evaluation) AND (non-valvular atrial fibrillation)". The literature search was not restricted by publication year.

\section{Inclusion and Exclusion Criteria}

The following inclusion criteria were considered (all must have been met):

- Economic evaluations of apixaban performed in any country;

- Economic evaluations of apixaban in the indication of stroke prevention in patients with NVAF;

- Any type of economic evaluation of apixaban (cost minimization analysis, cost-effectiveness analysis, cost-utility (CU) analysis, and cost-benefit analysis);

- Economic evaluations of apixaban or apixaban and other NOACs versus the gold standard (aspirin or warfarin or coumarin derivative) and other NOACs;

- Original articles.

The following exclusion criteria were considered (none must have been met):
- Economic evaluations of other NOACs excluding apixaban (dabigatran, rivaroxaban, and edoxaban);

- Economic evaluations of other anticoagulants excluding apixaban (warfarin, acenocoumarol, heparins, etc.);

- Other types of pharmacoeconomic studies with apixaban (budget impact analysis, cost/ burden of disease studies, etc.);

- Economic evaluations of apixaban in other indications aside from the target indication of this study (venous thromboembolism [VTE] prevention in patients undergoing total hip or knee replacement, VTE treatment, etc.);

- Article language other than Spanish, English, French, Portuguese, or Italian;

- Review articles, letters, commentaries, editorials, and papers that only report a study methodology without a result.

\section{Data Extraction}

The extraction process consisted of three steps once studies were identified after the search. First, some studies were excluded just by reading the title, mostly in the case of repeated records. Then, the inclusion and exclusion criteria were applied to limit the records to those that met the criteria. In a second review, the same criteria were applied after reading the selected abstracts to identify relevant studies. Finally, we proceeded to read the full articles of the selected records.

For all relevant articles after review, the main characteristics were recorded: title, authors, country, year of publication, journal (number, pages, etc.), main objective, type of evaluation, time horizon, type of model, perspective, comparator(s) against apixaban, sensitivity analysis, main results (incremental 
cost-effectiveness ratio [ICER]), and main conclusions.

The search was summarized in a CONSORT-style flowchart (PRISMA) [5].

\section{Quality Assessment}

In addition, a weighted version of Drummond's checklist [6] was used to further assess the quality of the selected studies [7]. The checklist is used specifically to assess economic evaluation studies, and it was divided into three main sections: study design, data collection, and the analysis and interpretation of results. The list consists of 35 items. The weighted version was used in the previous studies $[8,9]$ and assigns a maximum overall score of 119 (maximum scores of 26 for study design, 48 for analysis and interpretation of results, and 45 for data collection).

\section{Compliance with Ethics Guidelines}

This article is based on previously conducted studies and does not involve any new studies of human or animal subjects performed by any of the authors.

\section{RESULTS}

\section{Included Studies}

With the aforementioned search strategy: “(apixaban) AND (cost-effectiveness OR efficiency OR economic evaluation) AND (non-valvular atrial fibrillation)", 129 articles were found (53 articles from PubMed, 10 articles from Cochrane Library, 43 articles from Google Scholar, and 23 articles from the IME).

In the first review, after reading the titles of all the articles found, nine repeated articles were excluded from the four databases. After applying the inclusion and exclusion criteria, 80 more articles were excluded for the following reasons:

- 6 articles were economic evaluations of other NOACs;

- 10 articles were economic evaluations of apixaban for indications other than stroke prevention in patients with NVAF;

- 61 articles were not appropriate (studies on effectiveness or efficacy, on costs, in languages others than those listed in the exclusion criteria, on pharmacotherapeutic guidelines, etc.);

- 3 articles were review articles.

In the second review, after reading the abstracts of the 40 articles selected after the first review, 14 were discarded for not meeting the inclusion criteria:

- 7 were review articles;

- 4 were not economic evaluations; they were cost studies;

- 2 did not include apixaban among those NOACs tested;

- 1 referred to another article already listed. Finally, 26 articles were selected for full reading. After reading the articles, none of them were excluded (Fig. 1).

\section{Drummond's Checklist}

Table 1 shows the quality assessment results of the studies using the weighted version of Drummond's checklist [7]. All of the studies clearly defined the research question (item 1), the economic importance of the research question (item 2), the viewpoints of the analysis (item 3), the rationale for choosing the alternative programs (item 4), and the alternatives being compared (item 5). The mean for the "Study design" section was 20 out of 26, with a maximum of 26 and a minimum of 12 . All studies referenced the 

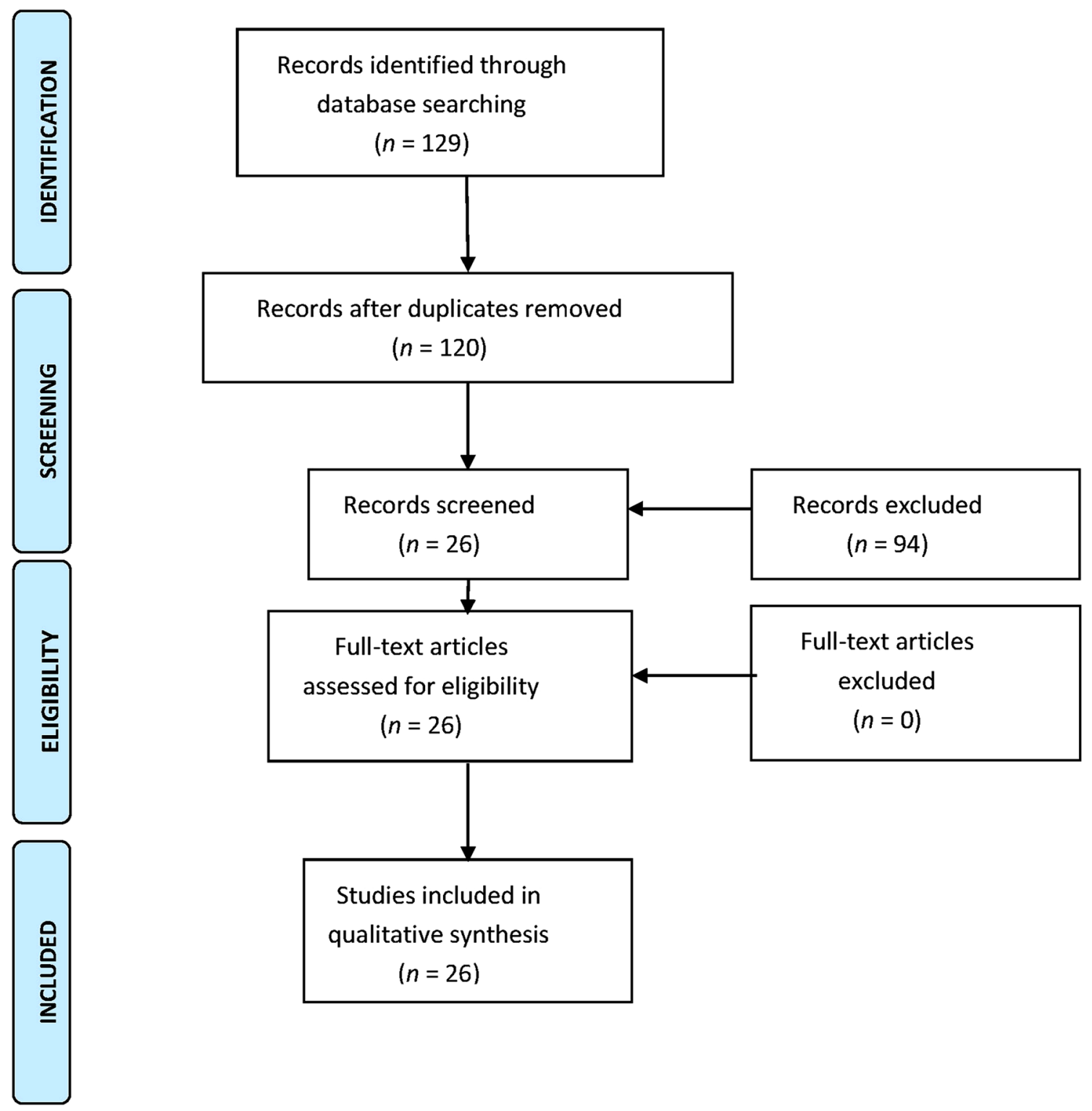

Fig. 1 CONSORT-type flowchart summarizing the study (PRISMA) [5]. The reasons for exclusion of records are summarized in the text ("Results" section)

source of the effectiveness estimates (item 8). In all the studies, the details of either the clinical trial or the meta-analysis of estimates are given (items 9 and 10), the primary outcome measures for the economic evaluation were reported (item 11), as were the methods to assess health states and other benefits (item 12), currency and price data were reported (item 18), details of any model used were given (item 20), and the choice of the model used and the key parameters, on which it was based were referenced (item 21). In summary, the "Data collection" section had a mean of 32 out of 45 , with a maximum of 42 and a minimum of 22 . The time horizon of costs and benefits was stated (item 22), as was the discount rate (item 23). The approach to sensitivity analysis was given (item 27). All the studies compared 
Table 1 Quality assessment results of the studies with the weighted Drummond's checklist [7]

\begin{tabular}{|c|c|c|c|c|}
\hline References & Study design & Data collection & Analysis and interpretation results & Final score \\
\hline [10] & 19 & 35 & 35 & 89 \\
\hline$[11]$ & 19 & 32 & 32 & 83 \\
\hline$[12]$ & 19 & 32 & 38 & 89 \\
\hline [13] & 19 & 35 & 35 & 89 \\
\hline [14] & 19 & 35 & 35 & 89 \\
\hline [15] & 19 & 35 & 35 & 89 \\
\hline [16] & 19 & 28 & 38 & 85 \\
\hline$[17]$ & 19 & 25 & 38 & 82 \\
\hline$[18]$ & 19 & 35 & 35 & 89 \\
\hline [19] & 19 & 42 & 42 & 103 \\
\hline [20] & 19 & 32 & 32 & 83 \\
\hline [21] & 19 & 32 & 39 & 90 \\
\hline [22] & 26 & 32 & 35 & 93 \\
\hline [23] & 19 & 32 & 31 & 82 \\
\hline [24] & 19 & 35 & 42 & 96 \\
\hline [25] & 26 & 25 & 42 & 93 \\
\hline [26] & 12 & 22 & 21 & 55 \\
\hline [27] & 23 & 38 & 29 & 90 \\
\hline [28] & 19 & 29 & 35 & 83 \\
\hline [29] & 19 & 29 & 39 & 87 \\
\hline [30] & 23 & 32 & 42 & 97 \\
\hline [31] & 23 & 35 & 39 & 97 \\
\hline [32] & 19 & 32 & 39 & 90 \\
\hline [33] & 19 & 29 & 42 & 90 \\
\hline [34] & 19 & 25 & 35 & 79 \\
\hline [35] & 19 & 29 & 39 & 87 \\
\hline Median & & & & 89 \\
\hline
\end{tabular}

relevant alternatives (item 30) and reported incremental analysis (item 31). Major outcomes were presented in a disaggregated and aggregated form (item 32) and studies answered the study questions (item 33) and presented conclusions (item 34). The mean for the third section "Analysis and interpretation of results" was 39, with a maximum of 42 and a 
minimum of 21. According to the weighted Drummond's checklist, the median quality score of selected studies was 89, with a minimum score of 55 , and a maximum score of 103.

The most relevant information from the 26 selected articles is summarized in Appendix 1 in the supplementary material.

\section{Article Characteristics}

The majority of cost-effectiveness evaluations were published recently (3 in 2012, 4 in 2013, 14 in 2014, and 5 in 2015) and reported the health economic data of apixaban in a very large number of countries: US (5), UK (4), Spain (3), Belgium (2), The Netherlands (2), Italy (2), Canada (1), Australia (1), Germany (1), Norway (1), France (1), Sweden (1), Slovenia (1), and Argentina (1).

All selected articles except one, which used a discrete events simulation model [26], used a Markov model to extrapolate long-term data; all the models derived effectiveness and safety data from randomized clinical trials. The majority of the models (73\%) included 8-14 health states, representing the main clinical outcomes in anticoagulated patients with atrial fibrillation (AF; ischemic stroke, hemorrhagic stroke, transient ischemic attack, systemic embolism, myocardial infarction, intracranial hemorrhages, other major hemorrhages, and minor bleeding).

All published evaluations except seven used the perspective of the payer, including only direct costs. Four studies [20, 29, 32, 34] presented the results from a societal perspective, and three studies [13-15] presented both societal and payer perspectives.

All publications except four used a lifetime horizon for the included subjects: two of them used a time horizon of 20 years [25, 34], one study used 30 years [32], and one study used a 1 -year period and a 10 -year period [25]. Utilities were generally assigned on the basis of previously published studies.

The articles by Dorian et al. [23] and Lip et al. [24] were the two models submitted to the National Institute for Health and Care Excellence for apixaban reimbursement by the National Health Service. Ten of the reviewed articles were adaptations of these models to different countries [10, 12-15, 18-21, 27].

Five studies compared apixaban with the standard therapy of warfarin or acenocoumarol $[10,14,28,33,34]$. Two studies compared apixaban with aspirin [18, 35]. Three studies compared apixaban with warfarin and aspirin $[20,23,27]$. One study compared apixaban with warfarin, aspirin, rivaroxaban, and dabigatran [21]. One study compared apixaban with rivaroxaban and dabigatran [24]. One study compared apixaban, rivaroxaban, and dabigatran with coumarin derivatives [17]. One study compared apixaban with vitamin $\mathrm{K}$ antagonists (VKAs) [19]. Eight studies compared warfarin with apixaban, dabigatran, and rivaroxaban [12, 16, 22, 25, 29-32]. One study compared apixaban with dabigatran [15], and one study compared apixaban with rivaroxaban [13]. Finally, two models compared the efficiency of warfarin with genotype-guided warfarin, apixaban, dabigatran, and rivaroxaban, and one of them also included edoxaban [11, 26]. All articles included both deterministic and probabilistic sensitivity analyses to study the model parameters that most influenced the ICER outcome and to assess the robustness of the model.

With the exception of eight studies, the rest only performed a CU analysis (cost/ quality-adjusted life year [QALY]) as a measure of the efficiency of the compared drugs. These eight studies performed a CU analysis (cost/ 
QALY) as well as a cost-effectiveness analysis (cost/life year gained) [13-17, 19, 27, 28].

All the selected articles based their results on the appropriate decision rates (incremental CU and cost-effectiveness ratios). When compared to adjusted-dose VKA (warfarin and acenocoumarol in the great majority of the articles), apixaban was invariably associated with a better clinical and safety profile. In addition, apixaban was cost-effective compared to warfarin and aspirin and the rest of the pharmacological strategies compared in most of the included economic evaluations according to the cost-effectiveness thresholds used in various countries (Table 2).

The mean incremental QALY of apixaban versus warfarin was of 0.219 , with a range of $0.137-0.5$, being dominant option in a study [33]. When comparing apixaban with aspirin, the mean incremental QALY was of 0.28 with a range of $0.27-0.29$, being a dominant option in a study [35].

In general, all the studies indicated that apixaban was cost effective with ICERs below the willingness-to-pay (WTP) threshold, if not dominant (Table 2). In evaluations performed in Europe, the mean ICER was of $€ 16,502 /$ QALY, with a range from $€ 7212 / \mathrm{QALY}$ to $€ 57,245 / Q A L Y$, while ICERs versus aspirin ranged from being dominant to $€ 7334 / \mathrm{QALY}$. In models performed in the US, ICERs of apixaban versus warfarin ranged from being dominant to $\$ 93,063 / \mathrm{QALY}$; in addition, apixaban was a dominant option versus aspirin in a study performed in the US [35].

In the deterministic sensitivity analysis, the results of these models were typically sensitive to changes in the cost of apixaban, baseline risk of stroke, decrease of utilities values, and time horizon. Upon the probabilistic sensitivity analysis, apixaban was deemed a cost-effective strategy in $73.4 \%$ of iterations (with a range of
42-99\%) compared to warfarin and 97.9\% (with a range of $96.7-99 \%$ ) when compared to aspirin.

\section{DISCUSSION}

$\mathrm{AF}$, the most common cardiac arrhythmia, is a well-established risk factor for stroke. Patients with AF are four-to-five times more likely to have embolic stroke or transient stroke than individuals without AF [36].

Until recently, VKAs, such as warfarin, acenocoumarol, and phenprocoumon, were the only available drugs for oral anticoagulation [37]. The numerous limitations of VKAs, such as prolonged action; substantial variations of the anticoagulant effect caused by numerous interactions with food, alcohol, other drugs, or genetic variations; and a narrow therapeutic window requiring close laboratory monitoring with dose adjustments, along with a perception of increased risk of bleeding with VKA therapy, have resulted in the underuse of oral VKAs and suboptimal stroke prevention in patients with AF [38, 39].

Apixaban, an oral direct factor Xa inhibitor, is the third NOAC to receive marketing authorization from the European Union for the prevention of stroke and systemic embolism in NVAF. It is the only NOAC that has been shown to be superior to dose-adjusted warfarin in terms of reducing stroke, systemic embolism, major bleeding, and all-cause mortality rates [40]. Since apixaban results in better health outcomes than VKAs (especially less major bleeding and a significant reduction in the stroke rate), it is crucial for health professionals and drug policy decision makers to know whether or not the routine use of apixaban in patients with NVAF is a cost-effective therapeutic option. 
Table 2 ICER value found in each study included in the systematic literature review along with the willingness-to-pay in the countries involved

\begin{tabular}{|c|c|c|c|}
\hline References & Country & ICER results & Threshold \\
\hline \multirow[t]{2}{*}[10]{} & Argentina & Apixa vs. War & USD 11,558/QALY \\
\hline & & USD 786.08/QALY & \\
\hline \multirow[t]{5}{*}[11]{} & Slovenia & Guided War: €6959/QALY & $€ 25,000 / \mathrm{QALY}$ \\
\hline & & Dabi: $€ 16,959 / \mathrm{QALY}$ & \\
\hline & & Riva: $€ 66,328 / \mathrm{QALY}$ & \\
\hline & & Apixa: $€ 15,679 / \mathrm{QALY}$ & \\
\hline & & Edoxa: $€ 18,994 /$ QALY vs. standard War & \\
\hline \multirow[t]{5}{*}[12]{} & Belgium & Dabi $110 \mathrm{mg}: € 13,564 / \mathrm{QALY}$ & $€ 30,000 / \mathrm{QALY}$ \\
\hline & & Dabi 150 mg: €7585/QALY & \\
\hline & & Riva: €7765/QALY & \\
\hline & & Apixa: €7212/QALY & \\
\hline & & vs. War & \\
\hline \multirow[t]{3}{*}{ [13] } & Spain & Apixa vs. Riva & $€ 30,000 / \mathrm{QALY}$ \\
\hline & & $€ 2347 / \mathrm{QALY}$ (NHS) & \\
\hline & & Dominant (societal) & \\
\hline \multirow[t]{3}{*}{ [14] } & Spain & Apixa vs. acenocoumarol & $€ 30,000 / \mathrm{QALY}$ \\
\hline & & $€ 13,305 / \mathrm{LYG}$ (NHS) & \\
\hline & & $€ 12,765 / \mathrm{QALY}$ (NHS) & \\
\hline \multirow[t]{6}{*}[15]{} & Spain & Apixa vs. Dabi $110 \mathrm{mg}$ & $€ 30,000 / \mathrm{QALY}$ \\
\hline & & $€ 1299 / \mathrm{QALY}$ (NHS) & \\
\hline & & Dominant (societal) & \\
\hline & & Apixa vs. Dabi $150 \mathrm{mg}$ & \\
\hline & & $€ 6591 / \mathrm{QALY}$ (NHS) & \\
\hline & & $€ 10,676 /$ QALY (societal) & \\
\hline$[16]$ & UK & Dabi was dominant vs. Riva, Apixa, and War & $£ 25,000 / \mathrm{QALY}$ \\
\hline
\end{tabular}


Table 2 continued

\begin{tabular}{|c|c|c|c|}
\hline References & Country & ICER results & Threshold \\
\hline [17] & $\begin{array}{l}\text { The } \\
\text { Netherlands/ } \\
\text { UK }\end{array}$ & $\begin{array}{l}\text { The Netherlands: } \\
\text { Riva: Dominated } \\
\text { Apixa: } € 13,024 / \text { QALY } \\
\text { Dabi: } € 14,626 / \text { QALY } \\
\text { UK: } \\
\text { Riva: Dominated } \\
\text { Apixa: Dominated } \\
\text { Dabi: } € 11,172 / \text { QALY vs. coumarin derivatives }\end{array}$ & $€ 20,000 / \mathrm{QALY}$ and $€ 36,000 / \mathrm{QALY}$ \\
\hline$[18]$ & Belgium & $\begin{array}{l}\text { Apixa vs. aspirin } \\
€ 7334 / \mathrm{QALY}\end{array}$ & $€ 30,000 / \mathrm{QALY}$ \\
\hline [19] & The Netherlands & $\begin{array}{l}\text { Apixa vs. VKAs } \\
€ 10,576 / \text { QALY }\end{array}$ & $€ 20,000 / \mathrm{QALY}$ \\
\hline$[20]$ & Sweden & $\begin{array}{l}\text { Apixa vs. } \\
\text { War: SEK 41,453/QALY } \\
\text { Aspirin: SEK 41,453/QALY }\end{array}$ & $\begin{array}{l}\text { For War and aspirin, above SEK } \\
35,000 \text { and SEK } 45,000 \text { per QALY, } \\
\text { respectively }\end{array}$ \\
\hline$[21]$ & France & $\begin{array}{l}\text { Aspirin, Dabi, and Riva were dominated by War } \\
\text { Apixa vs. War: } € 12,227 / \text { QALY }\end{array}$ & $€ 30,000 / \mathrm{QALY}$ \\
\hline [22] & Norway & $\begin{array}{l}\text { Sequential Dabi: } € 15,920 / \text { QALY } \\
\text { Apixa: } € 18,955 / Q A L Y \\
\text { Riva: } € 29,990 / \text { QALY } \\
\text { Dabi } 110 \text { mg: } € 66,121 / \text { QALY } \\
\text { vs. War }\end{array}$ & $\begin{array}{l}€ 79,000 / \text { QALY (NOK 588,000/ } \\
\text { QALY) }\end{array}$ \\
\hline$[23]$ & UK & $\begin{array}{l}\text { Apixa vs. War: } £ 11,909 / \text { QALY } \\
\text { Aspirin: } £ 7196 / Q A L Y\end{array}$ & $£ 20,000 / \mathrm{QALY}$ \\
\hline$[24]$ & UK & $\begin{array}{l}\text { Apixaban vs. Dabi 110: } £ 4497 / \text { QALY } \\
\text { Dabi 150: } £ 9611 / \text { QALY } \\
\text { Riva: } £ 5305 / \text { QALY }\end{array}$ & $£ 20,000 / \mathrm{QALY}$ \\
\hline$[25]$ & Germany & $\begin{array}{l}\text { Dabi } 110 \mathrm{mg}: € 294,349 / \mathrm{QALY} \\
\text { Dabi } 150 \mathrm{mg}: € 163,184 / \mathrm{QALY} \\
\text { Riva: } € 133,926 / \mathrm{Q} A L Y \\
\text { Apixa: } € 57,245 / \mathrm{Q} A L Y \\
\text { vs. War }\end{array}$ & $€ 50,000 / \mathrm{QALY}$ \\
\hline
\end{tabular}


Table 2 continued

\begin{tabular}{|c|c|c|c|}
\hline References & Country & ICER results & Threshold \\
\hline$[26]$ & UK & $\begin{array}{l}\text { Riva was dominated by Dabi and Apixa } \\
\text { Dabi was extensively dominated by Apixa } \\
\text { Genotype-guided War vs. War: } £ 13,226 / \text { QALY } \\
\text { Apixa vs. genotype-guided War: } £ 19,858 / \text { QALY }\end{array}$ & $£ 20,000$ to $£ 30,000 / \mathrm{QALY}$ \\
\hline$[27]$ & Italy & $\begin{array}{l}\text { Apixa vs. } \\
\text { Aspirin: €5600/QALY } \\
\text { War: €6800/QALY }\end{array}$ & $€ 20,000 / \mathrm{QALY}$ \\
\hline$[28]$ & Australia & $\begin{array}{l}\text { Apixaban vs. warfarin } \\
\text { AUD } 13,679 / \text { QALY }\end{array}$ & AUD 45,000/QALY \\
\hline$[29]$ & US & $\begin{array}{l}\text { Dabi: USD 140,557/QALY } \\
\text { Riva: USD 111,465/QALY } \\
\text { Apixa: USD 93,063/QALY } \\
\text { vs. War }\end{array}$ & USD 100,000/QALY \\
\hline$[30]$ & Italy & $\begin{array}{l}\mathrm{CHADS}_{2} \leq 1 \text {, Apixa and Dabi, €9631 and } \\
€ 7320 / \mathrm{QALY} \\
\mathrm{CHADS}_{2}=2 \text {, Apixa, Dabi, and Riva, €9660, } \\
€ 7609 \text {, and } € 20,089 / \text { QALY } \\
\text { In } \mathrm{CHADS}_{2} \geq 3 \text {, Apixa, Dabi, and Riva, €4723, } \\
€ 12,029 \text { and } € 13,063 / \mathrm{QALY} \\
\text { vs. War }\end{array}$ & $€ 25,000 / \mathrm{QALY}$ \\
\hline$[31]$ & Canada & $\begin{array}{l}\text { Dabi } 150 \mathrm{mg} \text { vs. War: CAD 20,797/QALY } \\
\text { Dabi } 110 \mathrm{mg} \text {, Apixa, and Riva were dominated by } \\
\text { Dabi } 150 \mathrm{mg}\end{array}$ & CAD 50,000/QALY \\
\hline$[32]$ & US & $\begin{array}{l}\text { Riva: USD 3190/QALY } \\
\text { Dabi: USD 11,150/QALY } \\
\text { Apixa: USD 15,026/QALY vs. warfarin }\end{array}$ & USD 50,000/QALY \\
\hline$[33]$ & US & Apixa vs. War was dominant & USD 50,000/QALY \\
\hline$[34]$ & US & $\begin{array}{l}\text { Apixa vs. War } \\
\text { USD } 11,400 / \text { QALY }\end{array}$ & USD 50,000/QALY \\
\hline$[35]$ & US & Apixa vs. aspirin was dominant at 10 years & USD 50,000/QALY \\
\hline
\end{tabular}

Apixa apixaban, AUD Australian Dollar, CAD Canadian Dollars, Dabi dabigatran, Edoxa edoxaban, ICER Incremental cost-effectiveness ratio, $L Y G$ life years gained, NHS National Health Service, NOK Norway Krone, QALY quality-adjusted life year, Riva rivaroxaban, SEK Swedish Krona, USD US Dollar, VKA vitamin K antagonist, War warfarin 
To answer this question, most of the cost-effectiveness studies included in this systematic review concur that patients treated with this drug have a higher life expectancy and more QALYs and life years gained than patients treated with VKAs. In addition, they also suggest that apixaban could result in savings from medical costs and hospitalizations for bleeding and routine international normalized ratio (INR) monitoring, but results in higher total medical costs over the patients' lifetime, mainly due to the increase in drug acquisition cost and because patients live longer.

All cost-effectiveness analysis were performed following the highest quality standard methodology to build analytical decision models and with scientific rigor, so the results will be valid and accurate; in fact, the quality of the economic evaluations was assessed as high, yet some quality items were not met. Moreover, most of economic evaluations applied a probabilistic sensitivity analysis, following the recommendations of some country guidelines to elaborate this kind of analysis and some health technology assessment agencies along with a cost-effectiveness acceptability curve, so it was possible to estimate probabilities of cost effectiveness at different WTP thresholds.

However, it was not possible to fully compare the economic evaluations, as the results were calculated on the basis of varying alternative treatment approaches, and thereby they were not fully homogeneous. It might be more accurate to compare apixaban treatment to the actual prescribing pattern of warfarin in clinical practice, as the treatment quality in a trial setting might be higher than in clinical practice due to a higher degree of monitoring.

Furthermore, variations in included costs, adverse events, annual discount rates, time horizons, comparators, and WTP thresholds contributed to a decrease in homogeneity, which makes it quite impossible to directly compare the ICERs of cost-effectiveness analysis included. In addition, the literature summarized in this review shows that NOACs versus warfarin are sensitive to how well INR is maintained with warfarin and the time frame over which the cost-effectiveness analysis is modeled; a longer time horizon and lower warfarin time in therapeutic range favor the new anticoagulants versus warfarin.

Even with these difficulties, the results of the cost-effectiveness analyses included in this systematic review show that apixaban could be considered as a cost-effective therapeutic alternative, because the cost/QALY is under the threshold value applied in the various countries where those analyses were conducted (the cost that healthcare systems or societies are willing to pay for an additional QALY gained), indicating that apixaban represents a good value-for-money for preventing stroke in patients with NVAF in several countries.

This systematic review has some limitations. The degree of uncertainty is an important limitation to the cost-effectiveness analysis of apixaban included. The model parameters obtained from the literature are imperfect or have uncertainty; this uncertainty can be substantial when the available research into that particular parameter is sparse (for instance, some model parameters, such as utilities and event rates, employed were derived from the 1990-2000s and may not reflect contemporary practice or outcomes). The selected studies, from countries around the globe, differ in their economic models, study perspectives, comparators, drug prices, presentation of results, and, especially, in the WTP thresholds. This variability in methodology was thus a challenge for comparing the different studies. 
In addition, it is difficult to analyze the results of the studies comparing apixaban [1, 2], dabigatran [41], and rivaroxaban [42], since they are based on studies and trials that use different populations with no similar basal risk, so the cost-effectiveness of different NOACs versus warfarin could vary in a model depending on baseline, patient-specific risk for ischemic stroke, and bleeding. The perspective of the payer was used in most of the studies, excluding costs other than direct medical costs from the analyses; if social perspective had been incorporated into the cost-effectiveness analysis, the results would have probably been different. Finally, all published models utilize a base case of a 70-year-old individual with AF. Given the need for anticoagulation for patients of different ages (in many occasion in patients below those age), it would be necessary to build models where base-case characteristics are obtained from unselected real-world population with AF that needs anticoagulation.

\section{CONCLUSIONS}

Different cost-effectiveness analyses suggest that apixaban is a cost-effective therapeutic option versus the gold standard therapy for stroke prevention in patients with NVAF in several countries. While variations in clinical events and costs do influence the efficiency rate of one drug relative to another, apixaban consistently appears to be most cost effective than VKAs and other NOACs.

The generalizability of the results of these cost-effectiveness analyses may be limited to the whole population of patients with NVAF, because efficacy and safety data are mainly restricted to patients who met inclusion criteria for the landmark apixaban trials. Furthermore, there are important differences between clinical trials and real-world practice that could produce different results if the cost-effectiveness analyses were performed using effectiveness data coming from daily medical practice instead of clinical trials. For these reasons, it is anticipated that data from daily medical practice in a real-world context will be very important for determining the real clinical and cost-effectiveness value of apixaban, thus helping to properly position apixaban within the current existing therapeutic arsenal for preventing stroke in patients with NVAF in several countries.

\section{ACKNOWLEDGMENTS}

This study was funded by BMS and Pfizer. The article processing charges for this publication were funded by BMS and Pfizer. All named authors meet the International Committee of Medical Journal Editors (ICMJE) criteria for authorship for this manuscript, take responsibility for the integrity of the work as a whole, and have given final approval for the version to be published.

Disclosures. Carme Pinyol is the owner of INNOVA-strategic consulting, an independent consultancy company, and received funds from BMS and Pfizer. José $\mathrm{M}^{\mathrm{a}}$ Cepeda has received funding for consultancy and lecturing from Daiichi Sankyo, Boehringer Ingelheim, BMS, and Pfizer. Inmaculada Roldán has received funding for lecturing from Astra-Zeneca, BMS-Pfizer, and Boehringer Ingelheim. Vanessa Roldán has received funding for consultancy from Boehringer Ingelheim, and for consultancy and lecturing from Bayer, Bristol-Myers Squibb, and Pfizer. Silvia Jiménez and Paloma González are employees of BMS. Javier Soto is an employee of Pfizer. 
Compliance with Ethics Guidelines. This article is based on previously conducted studies and does not involve any new studies of human or animal subjects performed by any of the authors.

Open Access. This article is distributed under the terms of the Creative Commons Attribution-NonCommercial 4.0 International License (http://creativecommons.org/licenses/ by-nc/4.0/), which permits any noncommercial use, distribution, and reproduction in any medium, provided you give appropriate credit to the original author(s) and the source, provide a link to the Creative Commons license, and indicate if changes were made.

\section{REFERENCES}

1. Granger CB, Alexander JH, McMurray JJV, et al. Apixaban versus warfarin in patients with atrial fibrillation. N Engl J Med. 2011;365:981-92.

2. Connolly SJ, Eikelboom J, Joyner C, et al. Apixaban in patients with atrial fibrillation. $\mathrm{N}$ Engl J Med. 2011;364:806-17.

3. Baglin T. The role of the laboratory in treatment with new oral anticoagulants. J Thromb Haemost. 2013;11(Suppl. 1):122-8.

4. Furie KL, Goldstein LB, Albers GW, et al. Oral antithrombotic agents for the prevention of stroke in nonvalvular atrial fibrillation: a science advisory for healthcare professionals from the American Heart Association/American Stroke Association. Stroke. 2012;43:3442-53.

5. Urrútia G, Bonfill X. PRISMA declaration: a proposal to improve the publication of systematic reviews and meta-analyses. Med Clin (Barc). 2010;135(11):507-11.

6. Drummond MF, Jefferson TO. Guidelines for authors and peer reviewers of economic submissions to the BMJ. BMJ. 1996;313:275-83.

7. La Torre G, Nicolotti N, de Waure C, Ricciardi W. Development of a weighted scale to assess the quality of cost-effectiveness studies and an application to the economic evaluations of
anti-HPV tetravalent vaccine. Italian J Public Health. 2011;19:103-11.

8. Radl KI, Ianuale C, Boccia S. A systematic review of the cost-effectiveness of lifestyle modification as primary prevention intervention for diabetes mellitus type 2. Epidemiol Biostat Pub Health. 2013;10(2). doi:10.2427/8846.

9. González FM, Veneziano MA, Puggina A, Boccia S. Systematic review on the cost-effectiveness of genetic and electrocardiogram testing for long QT syndrome in infants and young adults. Value Health. 2015;18:700-8.

10. Giorgi MA, Caroli C, Giglio ND, et al. Estimation of the cost-effectiveness of apixaban versus vitamin $\mathrm{K}$ antagonists in the management of atrial fibrillation in Argentina. Health Econ Rev. 2015;5(1):52.

11. Janzic A, Kos M. Cost effectiveness of novel oral anticoagulants for stroke prevention in atrial fibrillation depending on the quality of warfarin anticoagulation control. Pharmacoeconomics. 2015;33(4):395-408.

12. Kongnakorn T, Lanitis T, Annemans L, et al. Stroke and systemic embolism prevention in patients with atrial fibrillation in Belgium: comparative cost effectiveness of new oral anticoagulants and warfarin. Clin Drug Investig. 2015;35(2):109-19.

13. Canal Fontcuberta C, Betegón Nicolás L, Escolar Albaladejo G, De Salas-Cansado M, Rubio-Rodríguez D, Rubio-Terrés C. Cost-effectiveness analysis of apixaban versus rivaroxaban for prevention of stroke in patients with non-valvular atrial fibrillation in Spain. PharmacoEcon Span Res Artic. 2015;12(3):93-103.

14. Barón Esquivias G, Escolar Albaladejo G, Zamorano $\mathrm{JL}$, et al. Cost-effectiveness analysis comparing apixaban and acenocoumarol in the prevention of stroke in patients with non-valvular atrial fibrillation in Spain. Rev Esp Cardiol. 2015;68(8):680-90.

15. Betegón Nicolás L, Canal Fontcuberta C, Escolar Albaladejo $G$, et al. Cost-effectiveness analysis of apixaban versus dabigatran for prevention of stroke in patients with non-valvular atrial fibrillation in Spain. Eur J Clin Pharm. 2014;16(5):325-338.

16. Zheng Y, Sorensen SV, Gonschior AK, et al. Comparison of the cost-effectiveness of new oral anticoagulants for the prevention of stroke and systemic embolism in atrial fibrillation in a UK setting. Clin Ther Clin Ther. 2014;36(12):2015-28.

17. Verhoef TI, Redekop WK, Hasrat F, de Boer A, Maitland-van der Zee AH. Cost effectiveness of new oral anticoagulants for stroke prevention in 
patients with atrial fibrillation in two different European healthcare settings. Am J Cardiovasc Drugs. 2014;14(6):451-62.

18. Kongnakorn T, Lanitis T, Lieven A, Thijs V, Marbaix $S$. Cost effectiveness of apixaban versus aspirin for stroke prevention in patients with non-valvular atrial fibrillation in Belgium. Clin Drug Investig. 2014;34(10):709-21. (Erratum in: Clin Drug Investig. 2014;34(10):753. Annemans, Lievens [corrected to Lieven, Annemans]).

19. Stevanović J, Pompen M, Le HH, Rozenbaum MH, Tieleman RG, Postma MJ. Economic evaluation of apixaban for the prevention of stroke in non-valvular atrial fibrillation in the Netherlands. PLoS One. 2014;9(8):e103974.

20. Lanitis T, Kongnakorn T, Jacobson L, De Geer A. Cost-effectiveness of apixaban versus warfarin and aspirin in Sweden for stroke prevention in patients with atrial fibrillation. Thromb Res. 2014;134(2):278-87.

21. Lanitis T, Cotté FE, Gaudin AF, Kachaner I, Kongnakorn T, Durand-Zaleski I. Stroke prevention in patients with atrial fibrillation in France: comparative cost-effectiveness of new oral anticoagulants (apixaban, dabigatran, and rivaroxaban), warfarin, and aspirin. J Med Econ. 2014;17(8):587-98.

22. Wisløff T, Hagen G, Klemp M. Economic evaluation of warfarin, dabigatran, rivaroxaban, and apixaban for stroke prevention in atrial fibrillation. Pharmacoeconomics. 2014;32(6):601-12.

23. Dorian $\mathrm{P}$, Kongnakorn $\mathrm{T}$, Phatak $\mathrm{H}$, et al. Cost-effectiveness of apixaban vs. Current standard of care for stroke prevention in patients with atrial fibrillation. Eur Heart J. 2014;35(28):1897-906.

24. Lip GY, Kongnakorn $\mathrm{T}$, Phatak $\mathrm{H}$, et al. Cost-effectiveness of apixaban versus other new oral anticoagulants for stroke prevention in atrial fibrillation. Clin Ther. 2014;36(2):192-210.

25. Krejczy M, Harenberg J, Marx S, Obermann K, Frölich L, Wehling M. Comparison of cost-effectiveness of anticoagulation with dabigatran, rivaroxaban and apixaban in patients with non-valvular atrial fibrillation across countries. J Thromb Thrombolysis. 2014;37(4):507-23.

26. Pink J, Pirmohamed M, Lane S, Hughes DA. Cost-effectiveness of pharmacogenetics-guided warfarin therapy vs. alternative anticoagulation in atrial fibrillation. Clin Pharmacol Ther. 2014;95(2):199-207.
27. Pradelli L, Calandriello M, Di Virgilio R, Bellone M, Tubaro M. Comparative pharmacoeconomic assessment of apixaban vs. standard of care for the prevention of stroke in Italian atrial fibrillation patients. Farmecon Health Econ Ther Pathways. 2014;15(Suppl 1):15-25.

28. Ademi Z, Pasupathi K, Liew D. Cost-effectiveness of apixaban compared to warfarin in the management of atrial fibrillation in Australia. Eur J Prev Cardiol. 2015;22(3):344-53.

29. Canestaro WJ, Patrick AR, Avorn J, et al. Cost-effectiveness of oral anticoagulants for treatment of atrial fibrillation. Circ Cardiovasc Qual Outcomes. 2013;6(6):724-31.

30. Rognoni C, Marchetti M, Quaglini S, Liberato NL. Apixaban, dabigatran, and rivaroxaban versus warfarin for stroke prevention in non-valvular atrial fibrillation: a cost-effectiveness analysis. Clin Drug Investig. 2014;34(1):9-17.

31. Coyle D, Coyle K, Cameron C, et al. Cost-effectiveness of new oral anticoagulants compared with warfarin in preventing stroke and other cardiovascular events in patients with atrial fibrillation. Value Health. 2013;16(4):498-506.

32. Harrington AR, Armstrong EP, Nolan PE Jr, Malone DC. Cost-effectiveness of apixaban, dabigatran, rivaroxaban, and warfarin for stroke prevention in atrial fibrillation. Stroke. 2013;44(6):1676-81.

33. Lee S, Mullin R, Blazawski J, Coleman CI. Cost-effectiveness of apixaban compared with warfarin for stroke prevention in atrial fibrillation. PLoS One. 2012;7(10):e47473.

34. Kamel H, Easton JD, Johnston SC, Kim AS. Cost-effectiveness of apixaban vs warfarin for secondary stroke prevention in atrial fibrillation. Neurology. 2012;79(14):1428-34.

35. Lee S, Anglade MW, Meng J, Hagstrom K, Kluger J, Coleman CI. Cost-effectiveness of apixaban compared with aspirin for stroke prevention in atrial fibrillation among patients unsuitable for warfarin. Circ Cardiovasc Qual Outcomes. 2012;5(4):472-9.

36. Wolf PA, Abbott RD, Kennel WB. Atrial fibrillation as an independent risk factor for stroke: the Framingham study. Stroke. 1991;22:983-8.

37. Albers GW, Dalen JE, Laupacis A, Manning WJ, Petersen P, Singer DE. Antithrombotic therapy in atrial fibrillation. Chest. 2001;119(Suppl. 1):194S-206S. 
38. Holbrook AM, Pereira JA, Labiris R, et al. Systematic overview of warfarin and its drug and food interaction. Arch Intern Med. 2005;165:1095-106.

39. Katsnelson M, Sacco RL, Moscucci M. Progress for stroke prevention with atrial fibrillation: emergence of alternative OACs. Stroke. 2012;43:1179-85.

40. Lau YC, Lip GY. New advances in the treatment of atrial fibrillation: focus on stroke prevention. Expert Opin Pharmacother. 2014;15:2193-204.
41. Connolly SJ, Ezekowitz MD, Yusuf S, et al. Dabigatran versus warfarin in patients with atrial fibrillation. N Engl J Med. 2009;361(12):1139-51.

42. Patel MR, Mahaffey KW, Garg J, et al. Rivaroxaban versus warfarin in nonvalvular atrial fibrillation. N Engl J Med. 2011;365(10):883-91. 